\title{
Physical and cellular structure changes of Rastali banana (Musa AAB) during growth and development
}

\begin{abstract}
A study on the physical and physiological characteristics of Rastali bananas (Musa AAB) was carried out throughout the 12 weeks after emergence of the first hand to determine the optimum growth stage of Rastali bananas. The fruit length and diameter followed a trend similar to that observed in fruit fresh weight throughout fruit development, and three physiological stages (S1ï S3) of sigmoid growth were identified. The growth rate was slow during S1 (1st to 4th week), rapid during S2 (5th to 10th week) and remained constant during S3 (11th and 12th week). Peel cells underwent periclinal growth, which was accompanied by an increase in fruit peel and pulp thickness as the fruit developed. Moreover, the pulp colour became more vivid and yellow as the fruit developed. The peel moisture content decreased while pulp moisture content increased during fruit growth and development. The pulp firmness increased from the first until seventh week, and it decreased from the seventh week until twelfth week of the experiment. Carbon dioxide $(\mathrm{CO} 2)$ production was the highest at $\mathrm{S} 1$. However, $\mathrm{CO} 2$ production declined until the 10th week and remained constant at a low level of $50 \mathrm{~mL} \mathrm{kgī} 1$ hī 1 during S3. Ethylene (C2H4) could not be detected throughout fruit growth and development. Thus, Rastali bananas showed physiological maturity at week 11 and week 12 after emergence of the first hand with constant fruit growth.
\end{abstract}

Keyword: Physiological maturity; Respiration rate; Fruit growth; Fruit development; Anatomy and fruit growth prediction 